\title{
Objective method for selective reconstruction of multiple graft arteries to potentially reduce biliary complications
}

\author{
Yogesh Puri ${ }^{1}\left[\right.$ - Ashwin Rammohan ${ }^{1} \cdot$ Amadeo Marcos $^{1} \cdot$ Prof Mohamed Rela $^{1}$
}

Received: 12 July 2021 / Accepted: 14 July 2021 / Published online: 29 July 2021

(c) The Author(s), under exclusive licence to Springer-Verlag GmbH Germany, part of Springer Nature 2021

\section{Dear Editor,}

We thank Reddy et al. for their insightful comments and for highlighting points which further bolster our objective decision-making criteria for selectively reconstructing multiple arteries in living donor liver transplantation (LDLT) [1]. As highlighted by Reddy et al., left lobe grafts (LLG) have a higher propensity to have multiple arteries due to a variable origin of the segment 4 artery. Moreover, this has been presented in our article $(18 \%, p=0.0001)$ and also extensively reported in literature $[2,3]$.

The left hepatic duct is always divided flush with the hilar plate in the donor operation, and hence the distance before its division into segmental branches becomes irrelevant. Moreover, it is denuding the duct of this highly vascularized hilar plate/plexus which is more likely to result in biliary complications (BC). The authors' premise that a relatively long extrahepatic duct may possibly result in a higher rate of $\mathrm{BC}$ while intuitive is unfounded with regard to left lobe grafts (LLG); evidence in literature show no difference in the rates of BC between the right and left lobe LDLT [4].

The authors postulate how selective reconstruction of multiple arteries could potentially increase BC in LLG. Although noteworthy, their effort is speculative and finds scant support in published literature. We had performed a 30-year literature review of all studies on multiple arterial inflow in LDLT grafts. Interestingly, apart from one, none of the papers including ours showed an increased BC in LLG when only one artery was reconstructed. Moreover, even the paper which did show an increased rate of BC involved a very subjective decision-making process rather than an

Yogesh Puri

drypuri@gmail.com

1 The Institute of Liver Disease and Transplantation, Dr Rela Institute and Medical Centre, Bharath Institute of Higher Education and Research, No.07 CLC Works Road,

Chromepet, Chennai 600044, India objective method as proposed by Sugawara et al. and us $[1,3]$. As demonstrated in our data, we have had 85 LLG where 16 had dual arterial supply, of which only 4 (4.7\%) had both arteries reconstructed. We did not observe BC in any of these 16 patients. We believe the reason for low $\mathrm{BC}$ rate is the result of meticulous attention to the hepatic hilar plexus anatomy with careful dissection and avoidance of energy devices in hilar plate area. Furthermore, the double clamp test undisputedly affirms the presence of good cross communication between arterial arcades in an LDLT graft.

Numerous corrosion cast studies which formed the basis of our monograph on the hilar plate anatomy clearly show a well-defined rich hilar plate plexus with vigorous supply from the rex recess and reinforced by several feeder vessels originating from named graft arteries $1-1.5 \mathrm{~cm}$ proximal to the hilar plate [5]. Therefore, we believe that dividing the artery flush with the graft or a diathermy burn close to the hilar plate is more likely to compromise the hilar plexus and risk $\mathrm{BC}$ than the absolute length of the bile duct. As mentioned by the authors, when present, the segment 4 artery is likely to be smaller of the two arteries supplying an LLG. Dogmatically reconstructing a smaller second artery makes for a tedious and avoidable exercise.

We believe that the observation of pulsatile back bleed in donors as well as recipients after reconstructing the bigger artery, along with avoidance of damage to the hilar plexus, guarantees good outcomes. We again thank the authors for reviewing our article and validating our objective and failsafe method of ensuring a liver graft with multiple arteries is adequately arterialized.

\section{Data and material availability}

Data is available within the article.

Code availability Not applicable. 


\section{Declarations}

Ethics approval Not applicable.

Conflict of interest The authors declare no competing interests.

\section{References}

1. Puri Y, Palaniappan K, Rammohan A, Narasimhan G, Rajalingam R, Cherukuru R, Rela M (2021) Anatomical basis for selective multiple arterial reconstructions in living donor liver transplantation. Langenbecks Arch Surg. https://doi.org/10.1007/ s00423-021-02176-y

2. Uchiyama H, Harada N, Sanefuji K, Kayashima H, Taketomi A, Soejima Y et al (2010) Dual hepatic artery reconstruction in living donor liver transplantation using a left hepatic graft with 2 hepatic arterial stumps. Surgery. [cited 2021 Mar 13];147(6):878-86

3. Sugawara Y, Tamura S, Kaneko J, Iida T, Mihara M, Makuuchi M et al (2011) Single artery reconstruction in left liver transplantation. Surgery [cited 2021 Mar 13];149(6):841-5

4. Wang SF, Huang Y, Chen XP (2011) Biliary complications after living donor liver transplantation. Liver Transpl 17:1127-1136

5. Cho A, Gunji H, Koike N, Narumoto S, Asano T, Yamamoto H et al (2007) Intersegmental arterial communication between the medial and left lateral segments of the liver. Dig Surg [cited 2021 Mar 13];24(5):328-30

Publisher's note Springer Nature remains neutral with regard to jurisdictional claims in published maps and institutional affiliations. 